\title{
EL «DEFENSOR DEL PUEBLO» EN IBEROAMÉRICA. UNA PERSPECTIVA COMPARADA
}

\author{
PEDRO CARBALLO ARMAS \\ Profesor Contratado Doctor de Derecho Constitucional \\ Universidad de Las Palmas de Gran Canaria
}

\author{
SUMARIO \\ I. Introducción. \\ II. El Ombudsman en Iberoamérica. Una \\ perspectiva comparada. \\ III. Conclusiones.
}

\section{INTRODUCCIÓN}

Actualmente, las democracias modernas sufren una dura prueba, tanto por las injerencias externas derivadas de la interdependencia mundial de los mercados, que en gran medida marcan el rumbo socioeconómico de los Estados (el denominado "movimiento económico globalizador"), como por la intensa demanda interna de los ciudadanos que apremian a sus gobernantes a la búsqueda efectiva de soluciones a sus problemas. Como no podía ser de otra manera, esta legítima y ancestral reclamación de una verdadera justicia - como la primera virtud de las instituciones sociales ${ }^{1}$ — se topa en estos primeros compases del siglo XXI con el problema concreto de la defensa de los ciudadanos.

No es sencillo el debate que se puede suscitar a este respecto y, precisamente, es aquí donde las objeciones tal vez se han convertido ya en una constante de naturaleza crítica, pues a menudo las carencias de los sistemas judiciales pueden terminar por alejarlos de su propio significado, convirtiendo la defensa de los derechos en pura ilusión óptica para el ciudadano medio, que se desquicia ante el insoportable laberinto del proceso judicial ${ }^{2}$.

1 RAWLS, J., Teoría de la Justicia, Fondo de Cultura Económica, 1997, pág. 17.

2 En este sentido, véase: TOHARÍA, J.J., Opinión pública y justicia. La imagen de la Justicia en la Sociedad Española, Consejo General del Poder Judicial, Madrid, 2001; AA. VV.: El juez y su 
Frente a este planteamiento, sin embargo, no debe perderse de vista que la sociedad democrática, como sociedad pluralista, también es la sociedad abierta $^{3}$, y bajo esta consideración, desde hace algún tiempo muchas sociedades buscan nuevas fórmulas tendentes a mejorar la efectividad concreta de los derechos, experimentando así la acogida de nuevos actores en la búsqueda de otras formas de protección de los ciudadanos ${ }^{4}$.

En esto, ya los suecos habían tomado la delantera mucho tiempo atrás cuando idearon en la Constitución de 1809 una figura designada por el Parlamento - el Ombudsman - para garantizar los derechos de los ciudadanos mediante la supervisión de las actividades de la Administración Pública. En realidad, lo que se trataba de conseguir no era otra cosa que garantizar los derechos de los ciudadanos mediante la supervisión de la actividad de la Administración a través de un representante del pueblo, elegido por el Parlamento, aunque independiente del mismo ${ }^{5}$. Con esta visión, pues, surgió la figura del Ombudsman: un comisionado parlamentario con la básica función de supervisar las actividades de la Administración mediante un proceso sumario e informal, tras el cual emitía el correspondiente informe (no vinculante) en el que dejaba constancia a la Administración afectada sus sugerencias e, incluso, aquellas propuestas de reformas legislativas que pudiera considerar oportunas.

Junto a estas características, si hay que señalar un aspecto destacable del Ombudsman, elegiríamos sin duda el hecho de que si bien sus informes no resultan vinculantes, sus sugerencias son tenidas en cuenta por la Administración, que generalmente se inclina a obedecerlas ${ }^{6}$.

Sin duda, las bondades de la institución terminarían por dejar huella en la segunda mitad del siglo XX, donde la ombudsmanía se irá extendiendo paulatinamente por todo el mundo. Como tal, parece claro que entre los factores desencadenantes de la prosperidad del Ombudsman en tantos países tuvo mucho que ver su adaptación a las diversas características jurídico-políticas de cada país sin perder por ello su propia esencia. De ahí que, pese a las distinciones - normalmente visibles- de estas instituciones, puede afirmarse que el prototipo originario (el Ombudsman surgido en Suecia) ha experimentado diversas modificaciones para poder así adecuarse a las necesi-

imagen en la sociedad: pasado, presente y futuro, Consejo General del Poder Judicial, Madrid, 2001; AA. VV.: Lenguaje forense; Consejo General del Poder Judicial, Madrid, 2001.

3 Véase SARTORI, G., La sociedad multiétnica. Pluralismo, multiculturalismo y extranjeros, Taurus, Madrid, 2001, pág. 8.

4 Resulta sumamente interesante, en este sentido, el trabajo reciente de PÉREZ MARTELL, R., Mediación civil y mercantil en la Administración de Justicia, Tirant lo Blanch, Valencia, 2008.

5 FAIRÉN GUILlÉN, V., El Defensor del Pueblo-Ombudsman-, Centro de Estudios Constitucionales, Madrid, 1982, pág. 36.

6 FAIRÉN GUILLÉN, V., "Posibilidad y conveniencia de introducir a los "Ombudsmänen" en los ordenamientos jurídicos de naciones de habla ibérica?, Revista de Estudios Políticos (Nueva Época), n. ${ }^{\circ} 14,1980$, págs. 27-28.

7 Sobre esta denominación, véase POWELL, G.R., "Ombudsmanía", Parliamentarian, n.. 1, 1969. 
dades y a las características propias de cada país; esto es, la individualización de las propias características de la institución no hace otra cosa que cumplir con la adaptación que hace cada ordenamiento con sus circunstancias concretas $^{8}$.

\section{EL OMBUDSMAN EN IBEROAMÉRICA. UNA PERSPECTIVA COMPARADA}

Ahora bien, más allá de la expansión que ha logrado el Ombudsman por todo el mundo, así como sus diversas adaptaciones, cualquiera que haya tenido ocasión de familiarizarse con esta peculiar institución, habrá podido comprobar hasta qué punto existen diversas similitudes entre el Ombudsman español (el Defensor del Pueblo) y el resto de instituciones estatales análogas en el ámbito iberoamericano?.

Tal afirmación se basa en la existencia de ciertos principios y reglas institucionales que rigen el comportamiento orgánico y funcional del Ombudsman en Iberoamérica, lo que nos ha de permitir encuadrar después algunas observaciones conclusivas respecto de los puntos de encuentro existentes entre el modelo español y el resto de estas instituciones existentes en los países americanos de habla hispana y portuguesa ${ }^{10}$.

\section{II.1. La configuración del Ombudsman —el Defensor del Pueblo- EN ESPAÑA}

Pero vayamos por partes. Comencemos por esbozar algunas singularidades del Ombudsman en España. En este sentido, conviene recordar, de entrada, que su origen proviene del propio contexto constituyente ${ }^{11}$-el célebremente conocido como proceso de la transición ${ }^{12}$ 1990.

8 Con carácter general, véase ROWAT, D.C., El Ombudsman en el mundo, Teide, Barcelona,

9 Con carácter general, véase AA. VV.: Defensorías del Pueblo en Iberoamérica, Aranzadi, Pamplona, 2008.

10 Como ya hiciera notar Escobar Roca (AA. VV., Defensorías del Pueblo en Iberoamérica..., págs. 22-23), Brasil, Chile y Uruguay carecen de una figura de estas características. De otra parte, en la República Dominicana existe una regulación normativa pero la institución todavía no ha entrado en funcionamiento. También excluimos del presente estudio el caso particular de Puerto Rico.

11 Con carácter general puede verse una síntesis en RUBIO LLORENTE, F., La forma del poder (estudios sobre la Constitución), Centro de Estudios Constitucionales, Madrid, 1997, págs. 5-41. También, véase BLANCO VALDÉS, R., Introducción a la Constitución de 1978, Alianza Editorial, Madrid, 1998, págs. 26-31.

12 En sentido estricto, Bryant y Mokrzycki prefieren utilizar el término "transición" cuando se trata de llegar a una meta precisa, y no "transformación", pues es un término anodino que no implica ninguna expectativa de particulares resultados (The new great transformation? Change 
En dicho periodo se llevará a cabo la elaboración, entre otras cosas, del sistema de garantías de las libertades y derechos de la ciudadanía, y es en el seno de tales debates donde se vislumbrará la posibilidad de introducir la figura del Ombudsman como un claro exponente que podrá servir como complemento en la defensa de los derechos de los ciudadanos ${ }^{13}$.

and continuity in East Central Europe, London-New York, 1996, págs. 1-12; citado por MEZZETTI, L., Le democrazie incerte. Transizioni costituzionali e consolidamento della democrazia in Europa orientale, Africa, America Latina, Asia, CISR, n. ${ }^{\circ}$ 19, G. Giappichelli Editore, Torino, 2000, pág. 42). Sobre el proceso de transición en España, véase MORODO, R., La transición politica, Tecnos, Madrid, 1984.

13 Para una observación genérica sobre el Defensor del Pueblo en España, véase AA. VV.: «El Defensor del Pueblo (1. ${ }^{a}$ parte)", Boletín de Información del Ministerio de Justicia, n. ${ }^{\circ}$ 1507, 1988; AGUIAR DE LUQUE, L., ELVIRA PERALES, A., "Intervención del Defensor del Pueblo en procedimientos jurisdiccionales", Diez años de la Ley Orgánica del Defensor del Pueblo. Problemas y perspectivas, Universidad Carlos III de Madrid (Cátedra Joaquín Ruíz-Giménez), Madrid, 1992; AGUILAR FERNÁNDEZ-HONTORIA, J., "A propósito del Defensor del Pueblo: los rasgos definidores de la posición jurídica de los órganos auxiliares", Revista de Administración Pública, n. ${ }^{\circ}$ 109, 1986; A. ARADILLAS: Todo sobre el Defensor del Pueblo, Plaza y Janés, 1985; ASTARLOA VILLENA, F., El Defensor del Pueblo en España, Ensayos Jurídicos, Universitat de les Illes Balears, Palma de Mallorca, 1994; "Una introducción al estudio del Defensor del Pueblo", Cuadernos de la Cátedra Fadrique Furió Ceriol, Universidad de Valencia, n. ${ }^{\circ}$ 2, 1993; BALDIRA MUNTE, F., "La legitimación del Defensor del Pueblo para interponer recursos de inconstitucionalidad", Boletín de los Colegios de Abogados de Aragón, n. ${ }^{\circ}$ 133, 1994; BAR CENDÓN, A., "El Defensor del Pueblo en el ordenamiento jurídico español, El desarrollo de la Constitución española de 1978 (coord. RAMIREZ, M.,), Libros Pórtico, Zaragoza, 1982; CARBALlO ARMAS, P., El Defensor del Pueblo, Tecnos, Madrid, 2003; CARRILLO LÓPEZ, M., „El Defensor del Pueblo: ‘Factor de democratización?”, Revista Jurídica de Cataluña, n. ${ }^{\circ}$ 4, 1982; CARRO FERNÁNDEZ-VALMAYOR, J.L., "Defensor del Pueblo y Administración Pública", Estudios sobre la Constitución española (homenaje al profesor Eduardo García de Enterría), tomo III, Civitas, Madrid, 1991; DAPENA BAQUEIRO, M., Ley Orgánica del Defensor del Pueblo (Ombudsman), Instituto Nacional de Prospectiva, Madrid, 1980; FAIRÉN GUILLÉN, V., El Defensor del Pueblo —Ombudsman -, cit.; GALLEGO HUESCAR, C., SOLÉ, F., "El Defensor del Pueblo", Revista de la Facultad de Derecho de la Universidad Complutense, n. ${ }^{\circ}$ 67, 1982; GIL ROBLES y GIL DELGADO, A.: El Defensor del Pueblo, Civitas, Madrid, 1979; El control parlamentario de la Administración (el Ombudsman), INAP, Madrid, 1981; El Defensor del Pueblo. Comentarios en torno a una proposición de Ley Orgánica, Madrid, 1979; "El Defensor del Pueblo y el control parlamentario de la Administración", Anales de Derecho de la Universidad de Murcia, n. ${ }^{\circ}$ 10, 1987-1990; GINER DE GRADO, C., Los Ombusmen europeos. El Defensor del Pueblo, Colección Europa, 1986; El Defensor del Pueblo en la teoría y en la práctica, ed. Popular, Madrid, 1986; PELLÓN GARCíA, R., "Las metamorfosis del "Ombudsman"», Documentación Administrativa, n. ${ }^{\circ} 161,1974 ;$ "¿Un "Ombudsman" para España?", Documentación Administrativa, n. ${ }^{\circ}$ 170, 1976; PELLÓN RIVERO, R., El Defensor del Pueblo. Legislación española y Derecho Comparado, col. informe, servicio central de publicaciones de la Presidencia del Gobierno, $3^{\text {a }}$ ed., 1982; PEÑARRUBIA IZA, M., Ombudsman Militar y Defensor del Pueblo, Ed. Dilex, Madrid, 2001; PÉREZ CALVO, A., "Aspectos constitucionales del Defensor del Pueblo", Revista de Derecho Político, n. ${ }^{\circ} 4$, 1979; "Rasgos esenciales del Defensor del Pueblo según la Constitución y la Ley Orgánica 3/1981 de 6 de Abril", Revista de Derecho Político, UNED, n. ${ }^{\circ}$ 11, 1981; "Artículo 54", Comentarios a las Leyes Políticas (dir. ALZAGA VILLAAMIL, O.,), tomo IV, Edersa, Madrid, 1983; PÉREZ FRANCESCH, J.L., «El Defensor del Pueblo en España: balance de veinticinco años de experiencia constitucional", Revista de Estudios Políticos (Nueva Época), n. ${ }^{\circ} 128,2005$; RUÍZ-GIMENEZ, J., "El Defensor del Pueblo como institución constitucional, como problema y como utopía", Las Cortes Generales, Instituto de Estudios Fiscales, Madrid, 1987; SÁINZ MORENO, F., "Defensor del Pueblo y Parlamento (relaciones con las Cámaras)", Diez años de la Ley Orgánica 
Hay que advertir, no obstante, que históricamente la institución era desconocida en nuestro ordenamiento jurídico y, por consiguiente, es claro que será en la Constitución de 1978 donde surge por primera vez en España, inspirada en la figura sueca, la institución del Ombudsman.

A la vista de la redacción dada por la Carta Magna, puede observarse que se puso especial énfasis en determinar algunos de sus aspectos básicos, al tiempo que lo configurará denominándolo "Defensor del Pueblo" ${ }^{14}$. Así, el esquema básico que dibuja el texto constitucional destacará de la referida institución sus rasgos esenciales: alto comisionado de las Cortes Generales, designado por éstas para la defensa de los derechos comprendidos en el Título I, a cuyo efecto podrá supervisar la actividad de la Administración (art. 54 CE) $)^{15}$.

\section{A) Naturaleza jurídica del Defensor del Pueblo}

Para entender su propia naturaleza jurídica y, por consiguiente, su razón de ser, ya se ha dicho, la propia Constitución española permite identificar unos primeros rasgos (art. 54). Así: Se cataloga al Defensor del Pueblo como comisionado de las Cortes Generales, que le designa y ante quien rinde cuenta de sus actividades. Ejerce la defensa de los derechos comprendidos en el Título I de la Constitución (de ahí la comprensible ubicación de la institución en el mismo Título como instrumento garantista de las libertades y derechos fundamentales), a cuyo efecto puede supervisar la actividad de la Administración. Remite a una futura Ley Orgánica la regulación de su estatuto (en adelante, $\mathrm{LOPD}^{16}$ ). Está legitimado para interponer recursos de amparo y de inconstitucionalidad ante el Tribunal Constitucional (art. 162 CE).

del Defensor del Pueblo. Problemas y perspectivas, Universidad Carlos III de Madrid (Cátedra Joaquín Ruíz-Giménez), Madrid, 1992; SANTAMARÍA PASTOR, J.A., El Defensor del Pueblo y la Administración de Justicia. Mesa Redonda (Madrid, 1, 2 y 6 de Julio de 1981), Presidencia del Gobierno, Servicio Central de Publicaciones, $2^{a}$ ed., Madrid, 1983; VARELA SUANZES-CARPEGNA, J., "La naturaleza Jurídica del Defensor del Pueblo", Revista Española de Derecho Constitucional, n. ${ }^{\circ}$ 8, 1983; VERA SANTOS, J.M.,El Defensor del Pueblo en la Constitución y en los Estatutos de Autonomía, Centro de Estudios Políticos y Constitucionales, Madrid, 2002; VILLAGOMEZ CEBRIÁN, A.J., "Defensor del Pueblo y Tribunales de Justicia”, Revista La Ley, n. ${ }^{3}$ 3828, Madrid, 1995.

14 Según ha observado Aradillas (op. cit., págs. 117-118), esta denominación surgió en el seno de la formación política de Alianza Popular, siendo aceptada la misma por todos los demás partidos políticos.

15 Conviene notar que la naturaleza constitucional de la institución impide que la misma pueda ser suprimida o modificada en sus rasgos esenciales mediante una reforma legal ordinaria, de modo que ésta sólo puede producirse a través de una reforma constitucional. Así, según explica Gil Robles y Gil Delgado, la supervivencia del Defensor del Pueblo queda a salvo de cualquier vaivén electoral y su reflejo en la composición de las mayorías parlamentarias. De este modo, la institución sólo podrá modificarse en su esencia o desaparecer, a través de una reforma constitucional, lo que no resulta sencillo ni previsible dentro del lógico desarrollo de nuestro sistema político (GIL ROBLES y GIL DELGADO, A., El control parlamentario de la Administración..., pág. 240).

16 Ley 3/1981, de 6 de abril, del Defensor del Pueblo. 
Es claro, no obstante, que a partir de la sumaria descripción realizada por el propio texto constitucional, el ordenamiento jurídico despliega toda una serie de notas características de la institución que deben subrayarse:

a) El Defensor del Pueblo es un órgano auxiliar de las Cortes Generales. Sí, pero sobre todo y fundamentalmente debemos tener en cuenta que es un órgano unipersonal, auxiliar de las Cortes Generales - que lo elige y cesa y ante quien rinde cuenta de sus actividades-, pero de las que se mantiene funcionalmente independiente (art. 1 LODP).

La virtud que describe esta configuración del Defensor del Pueblo no impide, sin embargo, dejar de tener en cuenta que la legislación de desarrollo ha previsto la existencia de dos relevantes colaboradores: los Adjuntos. En ellos, podrá el Defensor del Pueblo delegar sus funciones y le sustituirán en el ejercicio de las mismas, y en los supuestos de imposibilidad temporal y en los de cese (art. 8 LODP).

b) El Defensor del Pueblo es un defensor de los derechos y libertades de los ciudadanos y, asimismo, un supervisor de las actividades de la Administración Pública. En realidad este criterio, según Pérez Calvo, vino a romper el esquema tradicional del Ombudsman, volcado fundamentalmente en la fiscalización de la Administración (arts. 1 y 9 LODP) ${ }^{17}$. Por tanto, el Defensor del Pueblo es un defensor de los derechos y libertades de los ciudadanos (a cuyo efecto podrá supervisar la actividad de la Administración) y un fiscalizador de las actividades de la Administración (en aquellos casos de maladministration). Como resultado, pues, de un lado, el Defensor del Pueblo ejerce la defensa de los derechos comprendidos en el Título I de la Constitución, para lo cual puede supervisar las actividades de la Administración (lo que podríamos denominar como protección no jurisdiccional de los derechos); de otro lado, actúa supervisando las actividades de la Administración, sin estar en supuestos relacionados con la conculcación de los derechos comprendidos en el Título I de la Constitución (la denominada maladministration).

c) El Defensor del Pueblo es un órgano de control. En lo que se refiere a este aspecto, el Defensor del Pueblo es sin duda un órgano de control, pues sus atribuciones le permiten actuar verificando que el funcionamiento de la Administración se ajusta a los parámetros establecidos de forma genérica en la Constitución (los derechos comprendidos en el Titulo I y el artículo 103.1 $\left.\mathrm{CE}^{18}\right)$.

d) El Defensor del Pueblo y la actividad jurisdiccional. El modelo español de Ombudsman permite constatar algunas otras importantes funciones que tradicionalmente han sido inusuales en este tipo de instituciones. Así, pues,

17 PÉREZ CALVO, A., "Rasgos esenciales del Defensor del Pueblo según la Constitución y la Ley Orgánica 3/1981 de 6 de Abril»..., pág. 71.

18 Art. 103.1. La Administración Pública sirve con objetividad los intereses generales y actúa de acuerdo con los principios de eficacia, jerarquía, descentralización, desconcentración y coordinación, con sometimiento pleno a la ley y al Derecho. 
está legitimado para acudir al Tribunal Constitucional a través del ejercicio del recurso de amparo y de inconstitucionalidad (art. $162 \mathrm{CE}$ ), así como intervenir ante la justicia ordinaria, instando acciones de responsabilidad civil, denuncias de conductas penales (arts. 25-26 LODP), o interviniendo en el procedimiento de Habeas Corpus ${ }^{19}$.

\section{B) Estatuto personal del Defensor del Pueblo}

Con independencia de las características básicas que presenta el Defensor del Pueblo, resulta necesario afrontar algunas otras cuestiones relativas al estatuto personal de la institución, más allá de su configuración como comisionado de las Cortes Generales.

Dicho lo cual, conviene precisar inmediatamente que su regulación jurídica establece una serie de condicionantes explícitos: a) El candidato deberá ser español, mayor de edad ${ }^{20}$, y encontrarse en pleno disfrute de sus derechos civiles y políticos (art. 3 LODP). b) Designación por mayoría cualificada (art. 2 LODP) ${ }^{21}$. c) Duración en el cargo por un periodo de cinco años (con posibilidad de reelección sin limitaciones), alejándolo así del periodo normal de duración de las Cortes Generales, a fin de garantizar aún más la independencia de la institución frente al Parlamento (art. 2 LODP). d) Cese en sus funciones por las causas expresamente tasadas en su estatuto (art. 5 LODP)22. e) Asignación de las prerrogativas de inviolabilidad, inmunidad, así como un aforamiento especial (inculpación y enjuiciamiento por la Sala Segunda del Tribunal Supremo) a fin de asegurarle una adecuada independencia en el desempeño del cargo (art. 6 LODP).

\section{C) Las actuaciones del Defensor del Pueblo}

Uno de los valores esenciales que presenta la institución del Defensor del Pueblo lo constituye, no cabe duda alguna, la simplicidad de la tramitación procedimental de sus actuaciones. Dicho procedimiento puede ilustrarse con una comprobación simple: su actuación puede iniciarse de oficio o a instancia

19 Esta posibilidad le viene dada por la Ley Orgánica 6/1984, de 24 de mayo, reguladora del procedimiento de Habeas Corpus (art. 3).

20 La Constitución española fija la mayoría de edad para los españoles en 18 años (art. 12).

21 Señala su normativa que será designado el candidato que obtenga una votación favorable de las tres quintas partes de los miembros del Congreso de los Diputados y de los miembros del Senado. Caso de no alcanzarse las mencionadas mayorías, sería suficiente la mayoría de tres quintos en el Congreso de los Diputados y la mayoría absoluta del Senado.

22 Señala su estatuto personal, que el Defensor del Pueblo podrá cesar por: renuncia, expiración del plazo de su nombramiento, muerte o incapacidad sobrevenida, actuar con notoria negligencia en el cumplimiento del cargo, o haber sido condenado, mediante sentencia firme, por delito doloso. 
de parte (indistintamente por cualquier persona física o jurídica que invoque un interés legítimo ${ }^{23}$ ), es gratuita, no necesita de asistencia técnica (Abogado o Procurador), presenta un carácter informal, y la resolución a que puede llegar no tiene fuerza coercitiva sobre la Administración afectada. Asimismo, periódicamente rinde cuenta de sus actividades ante el Parlamento a través de sus informes.

\section{II.2. UN APUNTE SOBRE LAS DIVERSAS EXPERIENCIAS DEL OMBUDSMAN EN IBEROAMÉRICA}

La cuestión ha de plantearse ahora desde una perspectiva comparatista a fin de poder constatar las singularidades de estas instituciones en el ámbito iberoamericano ${ }^{24}$, y así poder destacar las diversas analogías y variedades que presentan las mismas respecto del Ombudsman en España ${ }^{25}$.

De entrada, conviene señalar que la gran mayoría de estas instituciones han acogido la misma denominación que el Defensor del Pueblo español. Así, Argentina, Bolivia, Colombia, Ecuador, Panamá, Paraguay, Perú, y Venezuela optaron por otorgar a la institución la misma denominación. No obstante ello, también las diversas prescripciones de los ordenamientos jurídicos de aquella región han experimentado otras formulaciones. De este modo, en El Salvador y Nicaragua se le denomina "Procurador para la Defensa de los Derechos Humanos"; en Guatemala, "Procurador de los Derechos Humanos"; en Honduras es denominado "Comisionado Nacional de los Derechos Humanos"; México lo instituye como una "Comisión Nacional de los Derechos Humanos"; y Costa Rica lo denomina "Defensor de los Habitantes".

En esto, se podrá observar que más allá del carácter específico que presenta cada institución, en orden a un complejo de explicaciones históricas y jurídico-políticas que justifican su razón de ser, también resulta determinante la fuerza expansiva que han mostrado algunos modelos — caso del Defensor del Pueblo español- y, consecuentemente, su influencia en la configuración definitiva de dichas instituciones ${ }^{26}$.

23 Asimismo, la LODP permite que los Diputados, Senadores, y algunas Comisiones del Parlamento puedan solicitar al Defensor del Pueblo el inicio de investigaciones sobre actos, resoluciones, o conductas concretas de la Administración Pública que afecten a un ciudadano o grupos de ciudadanos (art. 10.2 LODP)

24 Sobre diversas experiencias para el fortalecimiento de estas instituciones, véase AA. VV.: El fortalecimiento del Ombudsman, Universidad de Alcalá, Madrid, 1999. También, véase AA. VV.: I Informe sobre Derechos Humanos. Migraciones, Dykinson, Madrid, 2003; AA. VV.: El Ombudsman en el sistema internacional de Derechos Humanos: contribuciones al debate, Dykinson, Madrid, 2008.

25 SÁNCHEZ AGESTA, L., Curso de Derecho Constitucional Comparado, Universidad de Madrid, Madrid, 1974, pág. 22

26 Ibidem, págs. 25-26. También, véase PEGORARO, L. y RINELLA, A.: “Concepto y evolución del Derecho Constitucional Comparado", AA. VV.: Nuevo Derecho Constitucional Comparado, Tirant lo Blanch, Valencia, 2000, pág. 36. 
En el plano que nos interesa, el hecho de intentar acoger diversas explicaciones acerca del Ombudsman en Iberoamérica — sin afectar en modo alguno a las propias características de cada institución- nos permitirá constatar la adaptación positiva de estas "magistraturas de persuasión" en el ámbito de aquella región.

Lo primero que hay que hacer notar es el carácter emblemático que las propias Constituciones han querido fijar respecto del Ombudsman en Iberoamérica, asignándole una función objetiva o materialmente dirigida a la defensa de los derechos de la ciudadanía, por lo general, en sus relaciones con la Administración. Así, aparecen configuradas en ese sentido las instituciones de Argentina, Bolivia, Colombia, Ecuador, El Salvador, Guatemala, Honduras, México, Nicaragua, Paraguay, Perú, y Venezuela ${ }^{27}$. Además de los textos constitucionales, y más allá de la relevancia constitucional que con preponderancia ha querido dársele en aquella región, también algunos Estados han optado por acoger este tipo de instituciones directamente en sus respectivas legislaciones de desarrollo, tales han sido los casos de Costa Rica ${ }^{28}$ y Panamá29.

Sobre la base de la pretendida independencia o autonomía funcional de los Defensores del Pueblo, es preciso verificar también la propia configuración que se desprende de las reglas que comportan su estatuto personal. Ello permite explicar ciertas exigencias, tales como los requisitos para la designación del titular de la institución, mayorías cualificadas en la elección, duración del mandato, incompatibilidades o prerrogativas. Como bien se comprende, los diversos criterios experimentados permiten sugerir una sistematización, agrupándolos en concreto como sigue:

a) En un primer orden, puede afirmarse que en Iberoamérica, con carácter general, el Ombudsman aparece configurado como un comisionado parlamentario $^{30}$, pues es en el Parlamento donde se le designa y cesa, y donde rinde cuentas de sus actividades ${ }^{31}$.

27 Art. 86 de la Constitución de Argentina; arts. 218-224 de la Constitución de Bolivia; arts. 281-284 de la Constitución de Colombia; arts. 214-216 de la Constitución de Ecuador; arts. 192 y 194 de la Constitución de El Salvador; arts. 273-275 de la Constitución de Guatemala; art. 59 de la Constitución de Honduras; art. 102.B de la Constitución de México; art. 138.9 de la Constitución de Nicaragua; art. 276 de la Constitución de Paraguay; arts. 161-162 de la Constitución de Perú; y arts. 280-283 de la Constitución de Venezuela.

28 La Defensoría de los Habitantes de la República de Costa Rica fue creada por la Ley n. ${ }^{\circ}$ 7319, de 17 de noviembre de 1992.

29 Ley n. ${ }^{\circ} 7$, de 5 de febrero de 1997.

30 En algunos supuestos, no obstante, la normativa permite algunas particularidades. Así, en el caso de Nicaragua (art. 8 de la Ley del Procurador para la Defensa de los Derechos Humanos de Nicaragua), se establece que se nombrará un Procurador y Subprocurador por la Asamblea Nacional tras consultar con las asociaciones civiles pertinentes. Asimismo, en México, la comisión correspondiente del Senado debe proponer una terna tras consultar a las organizaciones sociales representativas de los diversos sectores sociales, así como entre los organismos públicos y privados promotores o defensores de los derechos humanos (art. 10 de la Ley de la Comisión Nacional de los Derechos Humanos de México). De forma diferente, en Perú la convocatoria para la 
b) Los Defensores del Pueblo en Iberoamérica, con la excepción de México, son órganos de caracterización unipersonal. En efecto, el caso mexicano resulta estar configurado, como hemos dejado entrever, en torno a una Comisión. Pero, en todo caso, el órgano ejecutivo de dicha Comisión corresponde a un Presidente, que ejerce las funciones directivas y de representación legal de la Comisión ${ }^{32}$.

Por otra parte, conviene precisar que por lo general estas instituciones (con la salvedad de Colombia y la específica particularidad del caso mexica$\mathrm{no}^{33}$ ) han configurado en su normativa de desarrollo la figura del Adjunto, si bien varía ostensiblemente el número de componentes. Así, las legislaciones de Costa Rica, Panamá, Paraguay y Venezuela han previsto un único Adjunto $^{34}$, mientras que los ordenamientos de Argentina ${ }^{35}$, Ecuador $^{36}$, Guatemala ${ }^{37}, \mathrm{y}$ Honduras $^{38}$ verifica los Adjuntos en orden a dos miembros. De forma excepcional, Bolivia prevé en su legislación tres Adjuntos ${ }^{39}$, y tanto Nicaragua, El Salvador ${ }^{40}$, como Perú ${ }^{41}$ presentan una articulación algo más compleja de los mismos.

presentación de candidatos se publica en el diario oficial de dicho país A tal fin, después se podrán formular tachas, que deberán acompañarse con prueba documental (art. 3 de la Ley del Defensor del Pueblo de Perú).

31 Como bien señala Carpizo, a diferencia del Defensor del Pueblo español, los informes de la Comisión Nacional de los Derechos Humanos se realizan ante los tres poderes políticos (CARPIZO, J.: "Algunas semejanzas entre el Ombudsman español y el mexicano", AA. VV.: La Constitución de 1978 y el constitucionalismo iberoamericano, Centro de Estudios Políticos y Constitucionales, Madrid, 2003, pág. 555).

32 Art. 15 de la Ley de la Comisión Nacional de los Derechos Humanos de México.

33 En la legislación mexicana destaca la figura del Visitador General (hasta cinco Visitadores Generales estarán integrados en la Comisión Nacional) que, a su vez, puede ser auxiliado por Visitadores Adjuntos (arts. 5, 23-24 de la Ley de la Comisión Nacional de los Derechos Humanos de México).

34 Art. 10 de la Ley de la Defensoría de los Habitantes de la República de Costa Rica; art. 16 de la Ley del Defensor del Pueblo de Panamá; art. 11 de la Ley del Defensor del Pueblo de Paraguay. En el caso de Panamá, en un principio la legislación atribuyó la existencia de dos Adjuntos, si bien la reforma de 2005 vino a establecer un único Adjunto (RAMÍREZ CALDERÓN, C.: "Panamá", AA. VV.: Defensorías del Pueblo en Iberoamérica..., pág. 311). Por otro lado, si bien la ley venezolana establece la figura del Adjunto (art. 27), la normativa también especifica que se podrán crear Defensores especiales y nombrar otro tipo de Defensores (arts. 29 y 31)

35 Art. 13 de la Ley del Defensor del Pueblo de la República de Argentina.

36 Art. 9 de la Ley del Defensor del Pueblo de Ecuador.

37 Art. 11 de la Ley del Procurador de los Derechos Humanos de Guatemala.

38 Art. 13 de la Ley del Comisionado Nacional de los Derechos Humanos de Honduras.

39 Art. 14 de la Ley del Defensor del Pueblo de la República de Bolivia.

40 En el caso de Nicaragua, más allá de la figura del Subprocurador — que es elegido por la Asamblea Nacional-, el Procurador puede nombrar a los Procuradores Especiales que estime pertinentes, señalando expresamente la legislación algunos otros: el Procurador Especial de la Niñez y Adolescencia, Procurador Especial de la Mujer, Procurador de los Pueblos Indígenas y Comunidades Étnicas, y Procurador Especial de las Cárceles (art. 18). Del mismo modo ocurre en la normativa de El Salvador, al establecer, además de su titular, un Procurador Adjunto para la Defensa de los Derechos Humanos, los Procuradores Adjuntos para la Defensa de los Derechos de la Niñez y la Juventud, de la Mujer y la Familia, de Derechos Económicos, Sociales y Culturales, del Medio Ambiente, y de Derechos Civiles e Individuales, y los demás Procuradores Adjuntos 
c) Otro aspecto destacable que debe observarse con suma atención respecto de los Defensores del Pueblo en Iberoamérica es el referido a los condicionantes existentes para acceder al cargo. Como tal, hay que tener presente en este sentido que la existencia de diversos requisitos — que en nada afectan a los aspectos esenciales de la institución - aparecen bajo distintas exigencias en las normativas de estas instituciones. Así, muchas de las legislaciones establecen una edad mínima para poder ser titular de la institución, y que puede oscilar entre los veinticinco años (Nicaragua y Paraguay) ${ }^{42}$, treinta años (Argentina, Costa Rica, Honduras, y Venezuela) ${ }^{43}$, y treinta y cinco años (Bolivia, El Salvador; México, Panamá, y Perú ${ }^{44}$ ).

A este esquema hay que añadir, además, que algunos ordenamientos se alinean en la exigencia de que el titular de la institución sea profesional de las ciencias jurídicas — caso de Colombia, Ecuador, Guatemala, Honduras, y Perú 45 - frente a otras legislaciones que lo obvian, como ocurre en Argentina, Bolivia, El Salvador, Costa Rica, México ${ }^{46}$, Nicaragua, Panamá, Paraguay, y Venezuela.

d) Hay que tener presente, de otra parte, que casi todas las legislaciones establecen la necesidad de que los candidatos al cargo de Defensor del Pueblo deban obtener una mayoría abultada. Sea ésta por mayoría (Honduras ${ }^{47}$ ), mayoría absoluta (Colombia, Costa Rica y Panamá48), con el sesenta por

que el Procurador considere necesarios para el mejor cumplimiento de sus atribuciones constitucionales y legales (art. 13). Respecto de los derechos de la infancia, resulta sumamente interesante el trabajo colectivo de AA. VV.: El Ombudsman Iberoamericano y los Derechos de la Infancia, Universidad de Alcalá, Madrid, 1999.

41 La legislación peruana tan sólo señala que el Defensor del Pueblo estará auxiliado por Adjuntos, sin señalar su número (art. 7).

42 Art. 10 de la Ley del Procurador para la Defensa de los Derechos Humanos de Nicaragua; art. 7 de la Ley del Defensor del Pueblo de Paraguay.

43 Art. 4 de la Ley del Defensor del Pueblo de la República de Argentina; art. 4 de la Ley de la Defensoría de los Habitantes de Costa Rica; art. 5 de la Ley del Comisionado Nacional de los Derechos Humanos de Honduras; art. 18 de la Ley del Defensor del Pueblo de Venezuela.

44 Art. 8 de la Ley del Defensor del Pueblo de la República de Bolivia; art. 5 de la Ley del Procurador para la Defensa de los Derechos Humanos de El Salvador; art. 9 de la Ley de la Comisión Nacional de los Derechos Humanos de México; art. 8 de la Ley del Defensor del Pueblo de Panamá; art. 2 de la Ley del Defensor del Pueblo de Perú. En el caso de Ecuador, la Constitución establece que el candidato deberá tener los mismos requisitos que los exigibles a los Magistrados de la Corte Nacional de Justicia (art. 216). Asimismo, la normativa colombiana exige los mismos requisitos que para ser Magistrado de la Corte Suprema de Justicia, de la Corte Constitucional o del Consejo de Estado (art. 3).

45 Art. 3 de la Ley del Defensor del Pueblo de Colombia; art. 9 de la Ley del Procurador de los Derechos Humanos de Guatemala; art. 5 de la Ley del Comisionado Nacional de los Derechos Humanos de Honduras; art. 2 de la Ley del Defensor del Pueblo de Perú. Asimismo, la normativa ecuatoriana (art. 4) establece que el candidato deberá reunir los mismos requisitos que para ser Magistrado de la Corte Suprema de Justicia, con excepción del referente a la carrera judicial.

46 En la legislación mexicana se establece el carácter preferente del profesional de las ciencias jurídicas (art. 9).

47 Art. 4 de la Ley del Comisionado Nacional de los Derechos Humanos de Honduras.

48 Art. 281 de la Constitución de Colombia; art. 3 de la Ley de la Defensoría de los Habitantes de Costa Rica; art. 6 de la Ley del Defensor del Pueblo de Panamá. 
ciento (Nicaragua ${ }^{49}$ ), o mayoría cualificada de dos tercios (Argentina, Bolivia, Ecuador, El Salvador, Guatemala, México, Paraguay, Perú, y Venezuela ${ }^{50}$ ). Como tantas veces se ha apuntado, el objetivo de tal perspectiva no es otro que proporcionar una designación que cuente con el mayor consenso posible. Ello impide, fundamentalmente en los sistemas donde la mayoría resulta bastante cualificada, que el nombramiento pueda ser acaparado por una formación política, salvaguardando de este modo la neutralidad de la institución.

Resta decir, además que una vez designado, el titular de este tipo de instituciones está sujeto a un fuerte régimen de incompatibilidades que, sin duda, tienden a garantizar la independencia de dicha institución ${ }^{51}$.

e) Hay que hacer algunas observaciones, también, respecto de la duración en el cargo de estas instituciones. Así, encontramos en las diversas legislaciones mandatos (que pueden ser igual o no al de los parlamentarios) que oscilan entre los tres años (El Salvador ${ }^{52}$ ), cuatro años (Costa Rica, Ecuador y Colombia ${ }^{53}$ ), cinco años (Argentina, Bolivia, Guatemala, México, Nicaragua, Panamá, Paraguay y Perú ${ }^{54}$ ), seis años (Honduras ${ }^{55}$ ), o siete años (Venezuela ${ }^{56}$ ).

Estas prescripciones se complementan de forma general con la posibilidad de reelección del titular de la institución. Situación que en alguna nor-

49 Art. 8 de la Ley del Procurador para la Defensa de los Derechos Humanos de Nicaragua.

50 Art. 2 de la Ley del Defensor del Pueblo de la República de Argentina; art. 6 de la Ley del Defensor del Pueblo de la República de Bolivia; art. 3 de la Ley del Defensor del Pueblo de Ecuador; art. 4 de la Ley del Procurador para la Defensa de los Derechos Humanos de El Salvador; art. 10 de la Ley del Procurador de los Derechos Humanos de Guatemala; art. 10 de la Ley de la Comisión Nacional de los Derechos Humanos de México; art. 4 de la Ley del Defensor del Pueblo de Paraguay; art. 2 de la Ley del Defensor del Pueblo de Perú; art. 16 de la Ley del Defensor del Pueblo de Venezuela.

51 Arts. 7 y 9 de la Ley del Defensor del Pueblo de la República de Argentina; art. 9 de la Ley del Defensor del Pueblo de la República de Bolivia; arts. 3-4 de la Ley del Defensor del Pueblo de Colombia; art. 9 de la Ley de la Defensoría de los Habitantes de Costa Rica; arts. 5-6 de la Ley del Defensor del Pueblo de Ecuador; art. 7 de la Ley del Procurador para la Defensa de los Derechos Humanos de El Salvador; art. 9 de la Ley del Procurador de los Derechos Humanos de Guatemala; art. 10 de la Ley del Comisionado Nacional de los Derechos Humanos de Honduras; art. 12 de la Ley de la Comisión Nacional de los Derechos Humanos de México; art. 16 de la Ley del Procurador para la Defensa de los Derechos Humanos de Nicaragua; arts. 13-14 de la Ley del Defensor del Pueblo de Panamá; art. 8 de la Ley del Defensor del Pueblo de Paraguay; art. 6 de la Ley del Defensor del Pueblo de Perú; arts. 19-20 de la Ley del Defensor del Pueblo de Venezuela.

52 Art. 4 de la Ley del Procurador para la Defensa de los Derechos Humanos de El Salvador.

53 Art. 281 de la Constitución de Colombia; art. 3 de la Ley de la Defensoría de los Habitantes de Costa Rica; art. 3 de la Ley del Defensor del Pueblo de Ecuador.

54 Art. 3 de la Ley del Defensor del Pueblo de la República de Argentina; art. 6 de la Ley del Defensor del Pueblo de la República de Bolivia; art. 3 de la Ley de la Defensoría de los Habitantes de Costa Rica; art. 10 de la Ley del Procurador de los Derechos Humanos de Guatemala; art. 11 de la Ley de la Comisión Nacional de los Derechos Humanos de México; art. 9 de la Ley del Procurador para la Defensa de los Derechos Humanos de Nicaragua; art. 7 de la Ley del Defensor del Pueblo de Panamá; art. 4 de la Ley del Defensor del Pueblo de Paraguay; art. 2 de la Ley del Defensor del Pueblo de Perú.

55 Art. 4 de la Ley del Comisionado Nacional de los Derechos Humanos de Honduras.

56 Art. 16 de la Ley del Defensor del Pueblo de Venezuela. 
mativa aparece vedada (Colombia, Guatemala y Venezuela ${ }^{57}$ ), y que en algunas otras legislaciones tan sólo es posible por una vez (Argentina, Bolivia, Costa Rica, Ecuador, México, Panamá, y Perú ${ }^{58}$ ).

f) De otra parte, siguiendo una cierta tradición, las legislaciones de desarrollo de estas instituciones en Iberoamérica fijan una serie de causas tasadas para poder cesar al titular de las mismas ${ }^{59}$.

g) Asimismo, el esquema base de estas instituciones se complementa con una práctica reiterada: la configuración de una serie de prerrogativas, que deben ser entendidas justamente en conjunto como una técnica adecuada para que el Ombudsman pueda cumplir adecuadamente con sus atribuciones. Hay que notar al respecto, sin embargo, que estas características son bastante dispares en los diversos ordenamientos iberoamericanos ${ }^{60}$.

Resulta útil, también, para verificar en lo fundamental la realidad del Ombudsman en Iberoamérica, prestar atención a sus actuaciones. En este sentido, la consideración que realizan las diversas legislaciones se enmarcan bajo la perspectiva de un procedimiento que trata de configurarse bajo las notas de gratuidad, agilidad y rapidez en la tramitación y, en líneas generales, por la ausencia de formalismos. Asimismo, junto a esta forma de tecnicidad en la tramitación de las quejas, propia de estas "magistraturas de persuasión", estas instituciones asumen en el cumplimiento de sus funciones la obligación de presentar periódicamente informes al Parlamento.

57 Art. 281 de la Constitución de Colombia; art. 10 de la Ley del Procurador de los Derechos Humanos de Guatemala; art. 16 de la Ley del Defensor del Pueblo de Venezuela.

58 Art. 3 de la Ley del Defensor del Pueblo de la República de Argentina; art. 6 de la Ley del Defensor del Pueblo de la República de Bolivia; art. 3 de la Ley de la Defensoría de los Habitantes de Costa Rica; art. 3 de la Ley del Defensor del Pueblo de Ecuador; art. 11 de la Ley de la Comisión Nacional de los Derechos Humanos de México; art. 7 de la Ley del Defensor del Pueblo de Panamá; art. 2 de la Ley del Defensor del Pueblo de Perú.

59 Arts. 10-11 de la Ley del Defensor del Pueblo de la República de Argentina; arts. 12-13 de la Ley del Defensor del Pueblo de la República de Bolivia; art. 5 de la Ley del Defensor del Pueblo de Colombia; art. 6 de la Ley de la Defensoría de los Habitantes de Costa Rica; art. 7 de la Ley del Defensor del Pueblo de Ecuador; art. 9 de la Ley del Procurador para la Defensa de los Derechos Humanos de El Salvador; art. 12 de la Ley del Procurador de los Derechos Humanos de Guatemala; art. 11 de la Ley del Comisionado Nacional de los Derechos Humanos de Honduras; art. 14 de la Ley de la Comisión Nacional de los Derechos Humanos de México; arts. 11-13 de la Ley del Procurador para la Defensa de los Derechos Humanos de Nicaragua; art. 11 de la Ley del Defensor del Pueblo de Panamá; art. 5 de la Ley del Defensor del Pueblo de Paraguay; art. 4 de la Ley del Defensor del Pueblo de Perú; art. 22 de la Ley del Defensor del Pueblo de Venezuela.

60 Art. 12 de la Ley del Defensor del Pueblo de la República de Argentina; art. 10 de la Ley del Defensor del Pueblo de la República de Bolivia; art. 5 de la Ley del Defensor del Pueblo de Ecuador; art. 8 de la Ley del Procurador para la Defensa de los Derechos Humanos de El Salvador; art. 9 de la Ley del Procurador de los Derechos Humanos de Guatemala; art. 13 de la Ley de la Comisión Nacional de los Derechos Humanos de México; art. 15 de la Ley del Procurador para la Defensa de los Derechos Humanos de Nicaragua; art. 15 de la Ley del Defensor del Pueblo de Panamá; art. 8 de la Ley del Defensor del Pueblo de Paraguay; art. 5 de la Ley del Defensor del Pueblo de Perú; arts. 10 y 21 de la Ley del Defensor del Pueblo de Venezuela. Según observa Pierri Gonsebatt (PIERRI GONSEBATT, G. "Honduras", AA. VV.: Defensorias del Pueblo en Iberoamérica..., pág. 225), en un principio la legislación otorgaba inmunidad al Comisionado, pero tras la reforma posterior de la Constitución, tal prerrogativa quedó anulada. 
Pero la virtud de sus actuaciones no acaba ahí: los diversos ordenamientos iberoamericanos permiten, además de una tradicional función mediadora, que estas instituciones articulen acciones ante la justicia ordinaria y aun la constitucional, así como, por lo general, una labor de difusión, promoción y divulgación de los derechos humanos ${ }^{61}$.

\section{CONCLUSIONES}

Como habrá podido observarse, las diversas clasificaciones experimentadas pretenden, con mayor o menor resolución, subrayar los diversos aspectos —algunos análogos, otros diferentes_, que presenta el Ombudsman en Iberoamérica respecto del modelo español.

Así entendido, parece claro que en gran medida el Defensor del Pueblo español ha servido como referente a sus homólogos en Iberoamérica, y así, también en mayor o menor medida, la aplicación del esquema organizativo, la comprensión de su significación como "magistratura de persuasión" y, por las mismas razones, la ampliación de las tradicionales funciones hacia otras de variado orden.

A la vez, y junto a ese núcleo donde conviven referencias análogas, también resulta necesario subrayar que existen otros elementos, propios del carácter específico del ordenamiento jurídico de cada país y, justamente por ello, se puede constatar también la existencia de algunas diferencias.

De otra parte, y más allá de las insuficiencias que pudieran mostrar algunos de los modelos examinados, las ideas clasificatorias que han sido expuestas descansan sobre algunos elementos que, por sus especiales características técnico-jurídicas y operativas, resultan esenciales en la identificación del Ombudsman.

61 Arts. 14-32 de la Ley del Defensor del Pueblo de la República de Argentina, arts. 43 y 86 de la Constitución de Argentina; arts. 11, 18-34 de la Ley del Defensor del Pueblo de la República de Bolivia; arts. 7, 9, 14-17, 23-30, y 36 de la Ley del Defensor del Pueblo de Colombia, arts. 282 y 284 de la Constitución de Colombia; arts. 13, 15-28 de la Ley de la Defensoría de los Habitantes de Costa Rica; arts. 2, 8 y 12-28 de la Ley del Defensor del Pueblo de Ecuador; arts. 11-12 y 24-49 de la Ley del Procurador para la Defensa de los Derechos Humanos de El Salvador; arts. 13-16 y 20-32 de la Ley del Procurador de los Derechos Humanos de Guatemala; arts. 9 y 16-45 de la Ley del Comisionado Nacional de los Derechos Humanos de Honduras; arts. 6-8, 15, 24-73 de la Ley de la Comisión Nacional de los Derechos Humanos de México, y art. 105.II.g) de la Constitución de México; arts. 18 y $24-47$ de la Ley del Procurador para la Defensa de los Derechos Humanos de Nicaragua, y arts. 187-189 de la Constitución de Nicaragua; arts. 5 y 20-39 de la Ley del Defensor del Pueblo de Panamá; arts. 10 y 12-27 de la Ley del Defensor del Pueblo de Paraguay, arts. 133135 y 276 y 279 de la Constitución de Paraguay; arts. 9-31 de la Ley del Defensor del Pueblo de Perú; arts. 14, 25, 26, 41-61 de la Ley del Defensor del Pueblo de Venezuela. En este sentido, destaca la labor de tutela de los derechos de los pueblos indígenas (al respecto, véase AYLWIN, J., «Los Ombudsman y los derechos de los pueblos indígenas en América Latina", AA. VV.: Pueblos indígenas y derechos humanos, Universidad de Deusto, Bilbao, 2006, págs. 339-357; MOCTEZUMA BARRAGÁN, J., "Sistemas defensoriales de protección de los Derechos de los pueblos indígenas. La experiencia de México", Quórum. Revista de pensamiento iberoamericano, n. ${ }^{\circ} 21$, 2008, págs. 27-38). 
Hay que ser consciente, sin embargo, de la extraordinaria complejidad que encierra cualquier ejercicio tendente a efectuar hipótesis clasificatorias a resultas de los diversos elementos que hemos tomado en consideración. Pero, en todo caso, y pese a las dificultades que siempre pueden suscitarse, hemos de insistir ahora sobre algunas cuestiones a modo de consideraciones conclusivas:

Resulta claro, que primordialmente las Constituciones iberoamericanas - en consonancia con el modelo español - han optado mayoritariamente por incluir la figura del Ombudsman en sus textos. Es cierto, desde luego, que la exclusiva regulación ordinaria (casos de Costa Rica y Panamá) de estas instituciones no afecta, como tal, a su naturaleza jurídica. Ahora bien, más allá del apoyo legal, es preciso destacar que la expresa naturaleza constitucional de la institución del Ombudsman imposibilita que ésta pueda ser suprimida o modificada en sus aspectos esenciales a través de una reforma legal ordinaria.

En la línea marcada por el Defensor del Pueblo español, en líneas generales también se reconoce al Ombudsman como un comisionado parlamentario, pues es en el Parlamento donde se le elige y cesa, así como donde presenta sus informes. No obstante, resulta capital a este propósito hacer notar que algunos de los ordenamientos iberoamericanos determinan directamente otras exigencias que los alejan del prototipo español. Esto es verificable directamente observando las diversas reglas por las que se establece respecto de estas instituciones un determinado periodo de mandato, una edad mínima, o una concreta cualificación jurídica.

Debe subrayarse, también, que en las bases sustanciales de casi todas las legislaciones iberoamericanas se alude a la peculiar figura del Adjunto. Cabe pensar, a la vista de ello, que realmente esta formulación es en gran medida tributaria del modelo forjado en el ordenamiento español.

Por lo que respecta a la propia naturaleza de estas instituciones, puede sostenerse que las mismas aparecen revestidas con las características propias del Ombudsman: fiscalización de la Administración Pública (bien por la violación de los derechos de los ciudadanos o casos de maladministration) y simplicidad en la tramitación de las quejas (sin poder revocatorio o anulatorio de los actos de la Administración). En esto, conviene notar que dichas características básicas, presentes en la generalidad de los ordenamientos iberoamericanos, son también las que presiden la legislación del Defensor del Pueblo español.

Dada la estructura expuesta de estas instituciones, el sistema jurídico en el que se apoyan aparece configurado mayoritariamente en la exigencia de que la designación del titular de las mismas encuentre un amplio respaldo en el Parlamento a través de mayorías cualificadas. Hay que añadir a ello, que la estructura referida se completa con otras exigencias referidas a un sistema de prerrogativas e incompatibilidades, y no debe obviarse que estas características explícitas, lo hemos visto también, no hacen sino repetir básicamente los aspectos esenciales que recoge el modelo español. 
Finalmente, las diversas normativas examinadas revelan claramente que, en su generalidad, estas instituciones - más allá de una función mediadora y de promoción y difusión de los derechos humanos- pueden intervenir ante la justicia ordinaria y ante la justicia constitucional, desbordando en muchos casos las facultades alcanzadas en esta línea por el Defensor del Pueblo español.

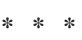

TiTLE: The Ombudsman in Latin America.

ASBTRACT: We can say that Latin America has not remained indifferent to the growing needs of society, proving once again its ability to adapt to new legal realities. Among other things, this approach is reflected in the configuration of the Ombudsman in the legal systems of the region and according to it, is to ascertain to what extent there are several similarities between the Spanish Ombudsman and other state institutions similar in Latin America.

RESUMEN: Resulta claro, con una simple observación, que Iberoamérica no ha permanecido impasible ante las necesidades crecientes de la sociedad, acreditando una vez más su capacidad de adaptación a las nuevas realidades jurídicas. Entre otras cosas, este criterio tiene su reflejo en la configuración del Ombudsman en los ordenamientos jurídicos de aquella región y, de acuerdo con el mismo, se pretende comprobar hasta qué punto existen diversas similitudes entre el Defensor del Pueblo español y el resto de instituciones estatales análogas en el ámbito iberoamericano.

KeY wORDs: Ombudsman.Human Rights. Public Administration. Civil Service. Parliamentary Commissioner.

Palabras Clave: Ombudsman. Defensor del Pueblo. Derechos Humanos. Administración Pública. Comisionado Parlamentario.

FECHA DE RECEPCIÓN: 09.05.2010. FECHA DE ACEPTACIÓN: 28.07.2010. 